\title{
Hyperoxia-Induced Pulmonary Vascular and Lung Abnormalities in Young Rats and Potential for Recovery
}

\author{
WENDY LEE WILSON, MICHELLE MULLEN, PETER M. OLLEY, AND \\ MARLENE RABINOVITCH \\ Departments of Cardiology and Pathology, Research Institute, The Hospital for Sick Children and Departments \\ of Pediatrics and Pathology, University of Toronto, Toronto, Canada
}

\begin{abstract}
We carried out morphometric studies to assess the effects of increasing durations of hyperoxic exposure on the developing rat lung and to evaluate the potential for new growth and for regression of structural abnormalities on return to room air. From day 10 of life Sprague-Dawley rats were either exposed to hyperoxia $\left(0.8 \mathrm{FiO}_{2}\right)$ for $2-8$ wk or were removed after 2 wk and allowed to "recover" in room air for 2-6 wk. Litter mates maintained in room air served as age matched controls. Every 2 wk experimental and control rats from each group were weighed and killed. The heart and lungs were removed, the pulmonary artery was injected with bariumgelatin, and the lung was fixed in formalin in the inflated state. Morphometric assessments were made of right and left ventricular weights, lung volume, axial artery lumen diameter, alveolar number and concentration, and arterial number, concentration and muscularity. Rats continuously exposed to hyperoxia and rats exposed for only 2 wk showed the same degree of impaired parenchymal lung growth, as judged by a decrease in the concentration and number of alveoli. A significant decrease in arterial concentration, increase in muscularization of peripheral arteries, and medial hypertrophy of muscular arteries occurred after 2 wk of hyperoxia. Despite an initial trend toward regression, these features became progressively severe with continued hyperoxic exposure and by 8 wk were associated with a decreased arterial lumen diameter, with right ventricular hypertrophy and with failure to thrive. In rats exposed to hyperoxia for 2 wk and then returned to room air there was a persistent decrease in arterial number and an increase in muscularization but both features were less severe than in rats continuously exposed. Thus, an 8-wk exposure to hyperoxia in rats from day 10 of life results in decreased lung and vascular growth and in increased muscularity. Even a relatively short 2 -wk exposure is associated with impaired alveolar growth and vascular abnormalities which persist into "adult" life. (Pediatr Res 19: 1059-1067, 1985)
\end{abstract}

\section{Abbreviations}

RA, room air

$R V$, right ventricular

$L V$, left ventricular

$\mathrm{S}$, septum

Received January 15, 1985; accepted June 4, 1985.

Requests for reprints should be addressed to Dr. Marlene Rabinovitch, Department of Cardiology, The Hospital for Sick Children, 555 University Avenue, Toronto, Ontario, Canada M5G 1 X8.

Supported by the Department of Zoology, Independent Studies Program, University of Toronto and by the Ontario Heart Foundation no. OHF 4-14. M.R. is a Research Associate of the Ontario Heart Foundation.
The newborn infant, especially the premature with hyaline membrane disease, may require prolonged high oxygen therapy. Hyperoxia is damaging to lung tissue presumably because the relatively inert $\mathrm{O}_{2}$ molecule undergoes univalent reduction to form highly reactive free radicals which are cytotoxic (1). Some protection is afforded by the antioxidant enzyme systems of the lungs, superoxide dismutase, catalase, and glutathione peroxidase $(2-5)$ but the induction of these enzymes is often insufficient to prevent tissue damage. In the clinical setting it has been difficult to separate the role of oxygen toxicity from other variables such as ventilator barotrauma and lung immaturity in the pathogenesis of bronchopulmonary dysplasia and in the development of the vascular changes which result in cor pulmonale (6).

In experimental studies, rodents exposed to hyperoxia during the first few days of life have impaired lung growth manifest by a reduction in the number of both alveoli (7) and arteries (8). While there is evidence from studies in mature rats that hyperoxia causes abnormal muscularization of the pulmonary arteries (9), it has not been determined whether this occurs, or is particularly severe, in the developing pulmonary vascular bed. It is also not known whether removing young rats from the hyperoxic environment during lung development will result in regression of structural abnormalities and in new growth of arteries and alveoli.

Our objectives were to determine by morphometric analysis of young rat lungs how increasing duration of exposure to hyperoxia would affect (i) alveolar growth, (ii) arterial growth in number, and (iii) arterial muscularity. We also wanted to evaluate whether a longer period of "recovery" in room air would further improve the arterial growth observed by Roberts et al. (8) after only 2 wk and whether there would be any concomitant change in alveolar growth and in arterial muscularity.

\section{METHODS}

Hyperoxic exposure of rats. In these studies we used 71 Sprague-Dawley rats from eight litters. On day 10 of life, half the rats from pooled litters, randomly chosen, were exposed to hyperoxia $\left(0.8 \mathrm{FIO}_{2}\right)$ and the others were maintained in RA. We chose to initiate exposure to $80 \%$ oxygen at day 10 of life since previous studies have shown that this level of oxygen is only tolerated for $3 \mathrm{wk}$ in younger rats (7).

A $12 \mathrm{ft}^{3}$ plexiglass chamber divided into two separate compartments was used to house the cages. One compartment was attached to an on-line "wall" oxygen source, while the other was open to room air. Gas flow through the hyperoxic compartment $(12-151 / \mathrm{min})$ maintained ambient temperature $\left(22 \pm 1^{\circ} \mathrm{C}\right)$ and humidity so that there was no condensation. Carbon dioxide was absorbed by barium hydroxide lime crystals and as measured daily prior to changing crystals was never found to rise above $0.06 \%$. Using a Beckman $\mathrm{O}_{2}$ gas analyzer, both compartments 
were monitored every $30 \mathrm{~min}$ for the first $12 \mathrm{~h}$ and demonstrated to be stable at $80 \pm 2 \%$ oxygen and $21 \pm 1 \%$ oxygen. The hyperoxic and room air environments then were monitored twice daily and consistently found to be within these ranges. The chamber was opened for 10 min each day to clean the cages and replenish food and water. At this time, dams were alternated between experimental and control litters to diminish the effect hyperoxia might have on maternal nutritional status and nursing ability (10). All rats were weaned at 21 days of age.

Rats from pooled litters previously designated as " $0.8 \mathrm{FIO}_{2}$ " or "RA" were sequentially assigned to 2-, 4-, 6- and 8-wk experimental periods. From some of the hyperoxic rat litters, rats chosen at random, were returned to room air after $2 \mathrm{wk}$ and designated as " $0.8 \mathrm{FIO}_{2}+\mathrm{RA}$." At $2,4,6$, and 8 wk after initiating the experiment, rats from each exposure group $\left(0.8 \mathrm{FIO}_{2}, 0.8 \mathrm{FIO}_{2}\right.$ + RA, RA) were weighed and killed and morphologic studies of the heart and lungs carried out. The number of rats analyzed in each group at each time is given in Table 1.

Preparation of heart and lungs. The rats were killed by an overdose of sodium pentobarbital $(300 \mathrm{mg} / \mathrm{kg})$, and the heart and lungs prepared for morphometric analysis (11). The pulmonary artery was cannulated via the right ventricle with polyethylene tubing (PE-20) which was sutured in place. The trachea was then cannulated just below the carina and the heart and lungs were removed en bloc. After a 1 -h incubation of the tissue at $37^{\circ} \mathrm{C}$ in physiologic saline, the pulmonary artery was injected at $73.5 \mathrm{~mm} \mathrm{Hg}$ for $5 \mathrm{~min}$ with a radiopaque barium gelatin mixture, maintained liquid at $60^{\circ} \mathrm{C}$. The hot barium solution is of a viscosity which, when injected at this pressure, will evenly distend all arteries down to a size of $20 \mu \mathrm{m}$ external diameter. Previous studies have shown that if injected at lower pressure, filling of arteries is uneven (11). The lungs were then inflated at $36 \mathrm{~cm} \mathrm{H}_{2} \mathrm{O}$ pressure with $10 \%$ formalin and perfused with fixative for 3 days, as shorter perfusion resulted in incomplete fixation. After fixation, the heart was removed from the lungs. The RV free wall was dissected from the $L V+S$ and each was weighed separately and expressed as the ratio $\mathrm{RV} /(\mathrm{LV}+\mathrm{S})(12)$. The lungs were then analyzed.

Lung volume was determined by water displacement and the lungs were $x$-rayed at $35 \mathrm{keV}$ for $0.4 \mathrm{~min}$. From an arteriogram of the barium-filled vessels, using a micrometer, the lumen diameter of the axial artery of the left lung was measured at the hilum and at distance 10,50 , and $90 \%$ from the hilum to the periphery where the vessel appeared to end. A $1 \mathrm{~cm}^{2}$ section was then taken from the middle portion of the left lung and processed for routine histology. Microscopic tissue sections were stained for elastin using the Van Gieson method.

Morphometric analysis. In each microscopic section, a minimum of 50 arteries was analyzed (13). Each artery was identified by its accompanying airway and classified accordingly as: preacinar, terminal bronchiolus, respiratory bronchiolus, alveolar duct, and alveolar wall. Muscularity was assessed in two ways. First, the artery was judged as completely muscular (completely surrounded by a muscular coat), partially muscular (partially surrounded), or nonmuscular. Using an eyepiece micrometer, the external diameter of each artery was measured; for the

Table 1. Number of rats in each group

\begin{tabular}{cccc}
\hline Group & Exposure & Period (wk) & $n$ \\
\hline A & $0.8 \mathrm{FIO}_{2}$ & 2 & 6 \\
B & $0.8 \mathrm{FIO}_{2}$ & 4 & 7 \\
C & $0.8 \mathrm{FIO}_{2}$ & 6 & 6 \\
D & $0.8 \mathrm{FIO}_{2}$ & 8 & 6 \\
E & $\mathrm{RA}$ & 2 & 10 \\
F & $\mathrm{RA}$ & 4 & 12 \\
G & $\mathrm{RA}$ & 6 & 6 \\
$\mathrm{H}$ & $\mathrm{RA}$ & 8 & 5 \\
$\mathrm{I}$ & $0.8 \mathrm{FIO}_{2}$ & $2+\mathrm{RA}-2$ & 6 \\
J & $0.8 \mathrm{FIO}_{2}$ & $2+\mathrm{RA}-4$ & 6 \\
K & $0.8 \mathrm{FIO}_{2}$ & $2+\mathrm{RA}-6$ & 6 \\
\hline
\end{tabular}

partially muscular and muscular arteries a percent wall thickness was calculated according to the following formula:

$$
\frac{2 \times \text { wall thickness }}{\text { external diameter }} \times 100=\text { percent wall thickness }
$$

Fifteen low power fields $(\times 250$ magnification) were then randomly selected and all the arteries and alveoli within the boundaries of a point counting grid of known dimension $\left(0.2 \mathrm{~mm}^{2}\right)$ were counted. Any field with an airway or blood vessel occupying more than $25 \%$ was rejected and the adjacent field substituted. We then calculated the mean number of alveoli $/ \mathrm{mm}^{2}$ and the number of arteries $/ \mathrm{mm}^{2}$; correcting for the shrinkage factor from the fixed specimen to the microscopic section. The shrinkage factor was similar in sections from control and experimental animals and required division of the values obtained from the microscopic slides by 1.32 .

The mean ratio of alveoli/arteries was also determined. Total alveolar number was calculated using the previously determined values for lung volume and alveoli $/ \mathrm{mm}^{2}$ according to the following formula:

$$
\text { total alveolar no.: } \frac{\left(\text { alveoli } / \mathrm{mm}^{2}\right)^{3 / 2}}{1.55 \times \sqrt{\mathrm{P}}} \times \text { lung volume }\left(\mathrm{mm}^{3}\right)
$$

1.55 is the spherical constant for the alveolus (14) and $P$ is the volume portion of alveoli, derived by point counting the microscopic sections (13), and was similar in all rat groups.

Table 2. Morphologic difference within groups over duration of

\begin{tabular}{|c|c|c|c|c|}
\hline & & $\begin{array}{c}2-4 \mathrm{wk} \\
p\end{array}$ & $\begin{array}{c}4-6 \mathrm{wk} \\
p \\
\end{array}$ & $\begin{array}{c}6-8 \mathrm{wk} \\
p\end{array}$ \\
\hline A. Growth & $\begin{array}{c}0.8 \mathrm{FrO}_{2} \\
0.8 \mathrm{FIO}_{2}+\mathrm{RA} \\
\mathrm{RA}\end{array}$ & $\begin{array}{l}<0.001 \\
<0.001 \\
<0.001\end{array}$ & $\begin{array}{l}<0.001 \\
<0.001 \\
<0.001\end{array}$ & $\begin{array}{c}-^{*} \\
<0.001 \\
<0.001\end{array}$ \\
\hline B. $\mathrm{RV} /(\mathrm{LV}+\mathrm{S})$ & $\begin{array}{c}0.8 \mathrm{FIO}_{2} \\
0.8 \mathrm{FIO}_{2}+\mathrm{RA} \\
\mathrm{RA}\end{array}$ & $\begin{array}{l}- \\
- \\
-\end{array}$ & $\begin{array}{l}- \\
- \\
-\end{array}$ & $\begin{array}{c}- \\
<0.01 \\
<0.05\end{array}$ \\
\hline C. Lung volume & $\begin{array}{c}0.8 \mathrm{FIO}_{2} \\
0.8 \mathrm{FIO}_{2}+\mathrm{RA} \\
\mathrm{RA}\end{array}$ & $\begin{array}{c}- \\
<0.05 \\
-\end{array}$ & $\begin{array}{c}<0.001 \\
- \\
<0.001\end{array}$ & $\begin{array}{l}- \\
- \\
-\end{array}$ \\
\hline D. Alveoli $/ \mathrm{mm}^{2}$ & $\begin{array}{l}0.8 \mathrm{FIO}_{2} \\
0.8 \mathrm{FIO}_{2}+\mathrm{RA} \\
\mathrm{RA}\end{array}$ & $\begin{array}{l}- \\
- \\
-\end{array}$ & $\begin{array}{l}- \\
- \\
-\end{array}$ & $\begin{array}{l}- \\
- \\
-\end{array}$ \\
\hline E. Total alveolar no. & $\begin{array}{l}0.8 \mathrm{FrO}_{2} \\
0.8 \mathrm{FIO}_{2}+\mathrm{RA} \\
\mathrm{RA}\end{array}$ & $\begin{array}{l}- \\
- \\
-\end{array}$ & $\begin{array}{c}<0.001 \\
- \\
<0.001\end{array}$ & $\begin{array}{l}- \\
-\end{array}$ \\
\hline F. Arteries $/ \mathrm{mm}^{2}$ & $\begin{array}{l}0.8 \mathrm{FIO}_{2} \\
0.8 \mathrm{FIO}_{2}+\mathrm{RA} \\
\text { RA }\end{array}$ & $\begin{array}{l}- \\
<0.05 \\
<0.01\end{array}$ & $\begin{array}{c}- \\
- \\
-\end{array}$ & $\begin{array}{c}- \\
- \\
<0.001\end{array}$ \\
\hline G. Arteries/100 alveoli & $\begin{array}{c}0.8 \mathrm{FlO}_{2} \\
0.8 \mathrm{FlO}_{2}+\mathrm{RA} \\
\mathrm{RA}\end{array}$ & $\begin{array}{c}- \\
- \\
<0.01\end{array}$ & $<\frac{-}{-}$ & $\begin{array}{c}- \\
<0.05\end{array}$ \\
\hline $\begin{array}{l}\text { H. Extension of mus- } \\
\text { cle }\end{array}$ & $\begin{array}{l}0.8 \mathrm{FIO}_{2} \\
0.8 \mathrm{FIO}_{2}+\mathrm{RA} \\
\mathrm{RA}\end{array}$ & $\begin{array}{c}<0.001 \\
<0.001 \\
-\end{array}$ & $\begin{array}{c}<0.01 \\
<0.01 \\
-\end{array}$ & $\begin{array}{c}<0.001 \\
- \\
-\end{array}$ \\
\hline I. Medial hypertrophy & $\begin{array}{c}0.8 \mathrm{FiO}_{2} \\
0.8 \mathrm{FiO}_{2}+\mathrm{RA} \\
\mathrm{RA}\end{array}$ & $\begin{array}{l}- \\
- \\
-\end{array}$ & $\begin{array}{c}- \\
<0.05 \\
-\end{array}$ & $\begin{array}{c}<0.05 \\
- \\
-\end{array}$ \\
\hline J. Lumen diameter & $\begin{array}{c}0.8 \mathrm{FiO}_{2} \\
0.8 \mathrm{FiO}_{2}+\mathrm{RA} \\
\mathrm{RA} \\
\end{array}$ & $\begin{array}{c}<0.05 \\
- \\
<0.01\end{array}$ & $\begin{array}{l}<0.001 \\
<0.001 \\
<0.001\end{array}$ & $\begin{array}{c}<0.05 \\
- \\
-\end{array}$ \\
\hline
\end{tabular}
experiment

${ }^{*} p \geq 0.05$. 
Analysis of data. Morphometric analysis of the heart and lungs was carried out without knowledge of the group to which the rats belonged. For statistical assessment, a one-way analysis of variance was used and when significant differences were found Duncan's multiple range test was used to compare the groups (15). A $p$ value $<0.05$ was considered significant. In the figures, mean value $\pm \mathrm{SE}$ is designated: $p$ values designated in the figures are given as difference from age-matched controls, whereas in the text and in Table $2 p$ values also refer to comparisons within groups over different periods of hyperoxic exposure or "recovery."

\section{RESULTS}

Growth. Control rats maintained in room air gained weight steadily throughout the experimental period (Table 2). Hyperoxia resulted in significant failure to thrive apparent by $8 \mathrm{wk}$ of exposure. Body weights of hyperoxic rats were reduced by $26 \%$ compared with those of room air rats $(p<0.001)$ (Fig. $1 A)$. Rats returned to room air after 2 wk of hyperoxia had only a transient growth lag.

$R V$ hypertrophy. In room air control rats, the ratio of $\mathrm{RV} /(\mathrm{LV}$ $+\mathrm{S}$ ) decreased over the duration of the experimental period ( $p$

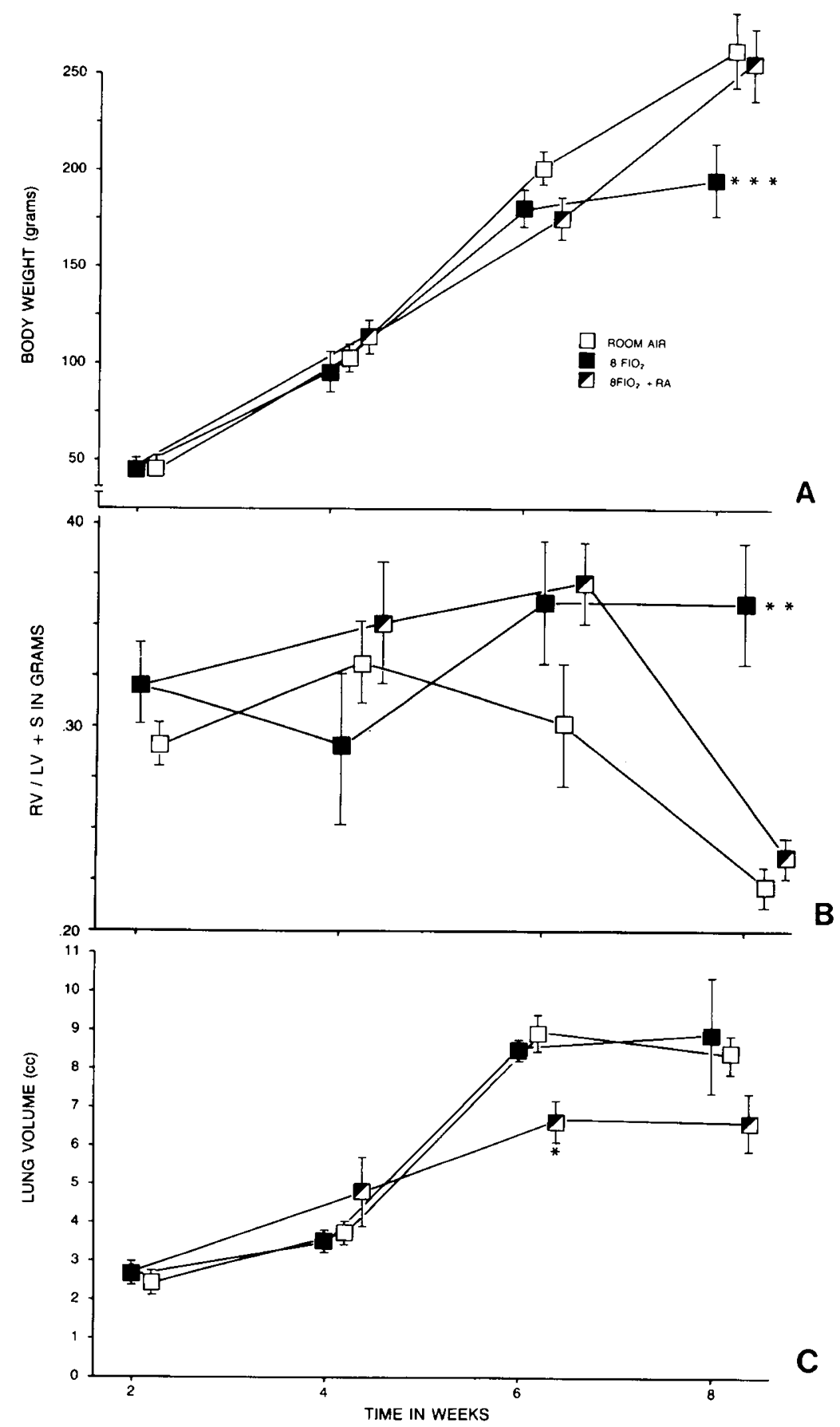

Fig. 1. A, growth. Weight in grams increased with age in RA (open square) and in rats returned to RA after 2 wk hyperoxic exposure $\left(0.8 \mathrm{FiO}_{2}+\right.$ $\mathrm{RA}$, half closed square). Rats continuously exposed $\left(0.8 \mathrm{FiO}_{2}\right.$, closed square $)$ failed to gain weight after 6 wk. $B$, RV hypertrophy. The ratio of RV/ $(\mathrm{LV}+\mathrm{S})$ decreased after $4 \mathrm{wk}$ in RA rats and after $6 \mathrm{wk}$ in $0.8 \mathrm{FIO}_{2}+\mathrm{RA}$. Rats continuously exposed to $0.8 \mathrm{FIO}_{2}$ did not show this change, resulting in $\mathrm{RV}$ hypertrophy by $8 \mathrm{wk}$. $C$, lung volume. In all groups, lung volume increased with age for the first 6 wk of the experiment, but $0.8 \mathrm{FiO}{ }_{2}+\mathrm{RA}$ rats had a decreased lung volume relative to other groups. Asterisks show $p$ values for significant difference from age matched controls: ${ }^{*} p<0.05$, $* * p<0.01, * * * p<0.001$. 

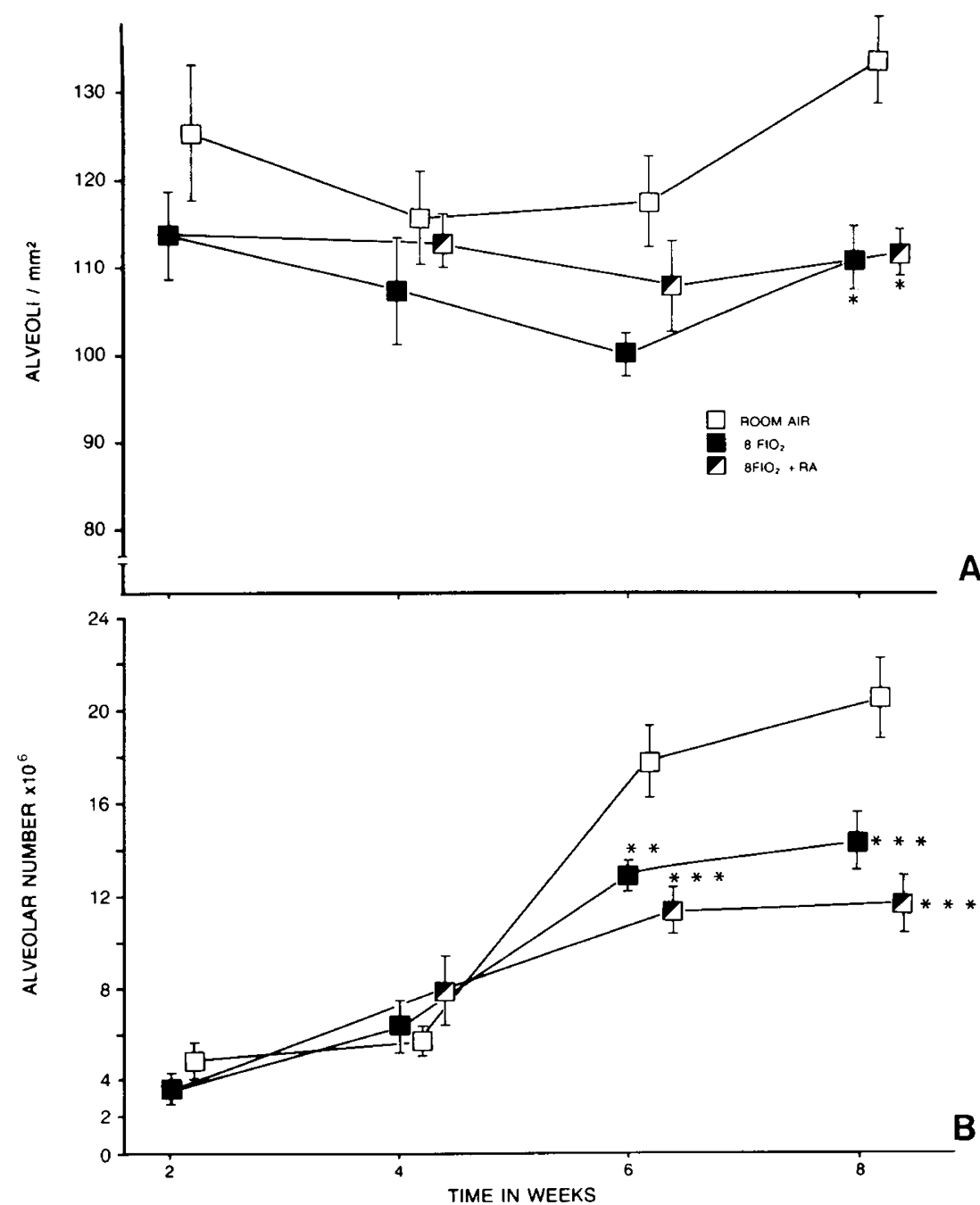

Fig. 2. $A$, alveolar concentration. Alveolar concentration (alveoli $/ \mathrm{mm}^{2}$ ) was similar in control RA rats over the duration of the experiment. A decreased alveolar concentration was evident in both $0.8 \mathrm{FrO}_{2}$ and $0.8 \mathrm{FIO}_{2}+\mathrm{RA}$ rats by the end of the experiment $\left({ }^{*} p<0.05\right) . B$, total alveolar number. RA rats showed an increased in alveolar number between 4 and $6 \mathrm{wk}$ of the experiment (see Table 2 for $p$ values). This did not occur in $0.8 \mathrm{FiO}_{2}$ or $0.8 \mathrm{FIO}_{2}+\mathrm{RA}$ rats, resulting in decreased alveolar number by $6 \mathrm{wk}\left({ }^{* * *} p<0.001\right)$.

$<0.05$ ) (Table 2). Continued hyperoxic exposure prevented this normal decline $(p<0.01)$ (Fig. $1 B)$. Separate measurements of $\mathrm{RV}$ and $\mathrm{LV}+\mathrm{S}$ adjusted for body weight indicate that the hyperoxic response was due to $\mathrm{RV}$ hypertrophy. In rats returned to RA after a 2-wk hyperoxic exposure the decrease in $\mathrm{RV} /(\mathrm{LV}$ + S) was only delayed: by the end of the experimental period these animals were similar to controls.

Parenchymal lung growth. In RA control rats, lung volume increased during the first $6 \mathrm{wk}$ of the experiment (Table 2). A "burst" of lung growth was apparent between 4 and 6 wk $(p<$ 0.001 ), but between 6 and 8 wk there was no further increase. A similar pattern was observed in rats continuously exposed to hyperoxia. Return to RA after 2 wk of hyperoxia, however, initially decreased the rate of lung growth in volume, by approximately $20 \%(p<0.05)$ (Fig. $1 C)$.

Alveolar concentration (no. $/ \mathrm{mm}^{2}$ ) was similar in control RA rats over the duration of the experiment (Table 2). Continued hyperoxic exposure resulted in a significant decrease in alveolar concentration by $22 \%(p<0.05)$ (Fig. $2 A)$. Rats returned to RA after 2 wk of hyperoxia and had same degree of decreased alveolar concentration as rats continuously exposed.

In control rats maintained in RA there was an increase in total alveolar number between 4 and 6 wk of the experiment $(p<$
0.001 ) (Table 2). Continuous hyperoxic exposure decreased the rate of alveolar proliferation compared to age-matched controls by $42 \%(p<0.001)$ (Fig. $2 B)$. This was not prevented by returning rats to $\mathrm{RA}$ after a 2 -wk exposure.

Pulmonary vascular structure and growth. In control rats maintained in RA there were two bursts of arterial proliferation judged both by an increased number of arteries $/ \mathrm{mm}^{2}$ and by an increased number of arteries $/ 100$ alveoli. The first occurred between 2 and 4 wk of the experiment ( $p<0.01$ for both parameters) and the second between 6 and $8 \mathrm{wk}(p<0.001$ and 0.05 for each respectively) (Table 2 ). Continued hyperoxic exposure prevented both these bursts, and arterial concentration was reduced by $73 \%(p<0.001)$ (Fig. $3 A$ and $B$ ). This could also be appreciated qualitatively in arteriograms as early as 4 wk (Fig. 4 $A$ and $B$ ). In rats returned to RA after 2 wk of hyperoxia, the first burst of arterial growth was delayed, and the second had not occurred by the end of the experiment (Table 2). Arterial concentration was reduced by $26 \%(p<0.001)$ (Fig. $3 A)$. This was apparent when assessing the absolute arterial concentration per $\mathrm{mm}^{2}$ (Fig. $3 A$ and $B$ ) rather than the arterial concentration relative to alveoli, and hence was a feature independent of the decreased alveolar concentration.

In control animals maintained in RA an expected $10 \%$ of 


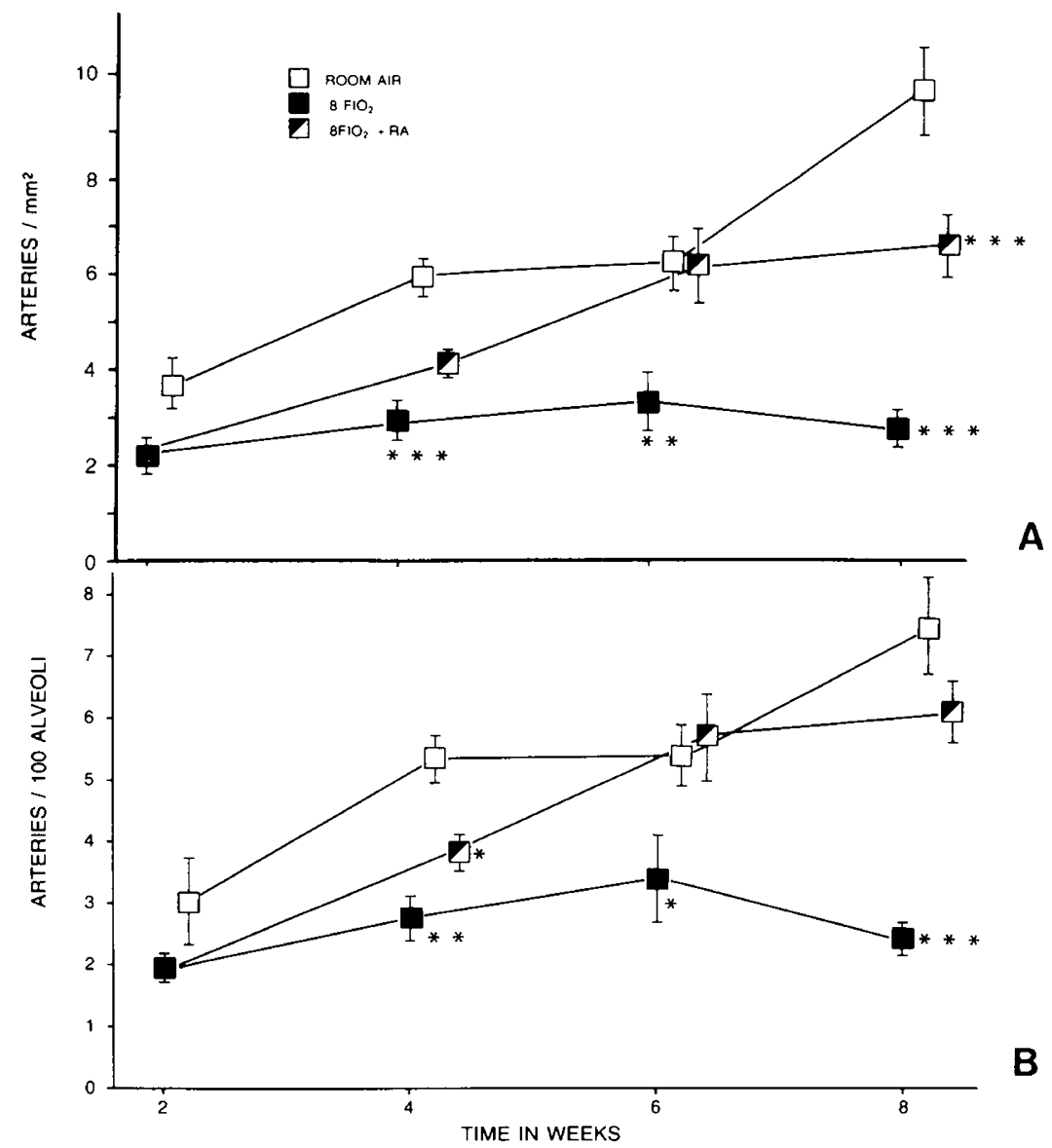

Fig. 3. Arterial concentration. RA control rats showed an increase in the concentration of arteries both in no./ $\mathrm{mm}^{2}(A)$ and relative to alveoli $(B)$ between 2 to $4 \mathrm{wk}$ and between 6 to $8 \mathrm{wk}$ of the experiment (see Table 2 for $p$ values). In $0.8 \mathrm{FrO}_{2}$ rats, neither of these bursts of arterial proliferation were evident. $\mathrm{In} 0.8 \mathrm{FiO}_{2}+\mathrm{RA}$ rats, the first burst was delayed, the second had not occurred by the end of the experiment.

alveolar duct arteries were muscularized (11) (Fig. 5A). Hyperoxia induced significant extension of muscle into peripheral arteries by 2 wk of exposure $(p<0.05)$ (Fig. $5 A)$, which was more severe at $4 \mathrm{wk}(p<0.001)$ (Table 2). There was some "adaptation" by $6 \mathrm{wk}$, i.e. a decrease in the severity of this feature $(p<0.01)$, but progressive extension occurred between 6 and 8 wk $(p<0.001)$ and $92 \%$ of alveolar duct arteries became muscularized.

In rats returned to RA after 2 wk of hyperoxia extension of muscle was progressively severe over the next $4 \mathrm{wk}$ (2-4 wk, $p<$ $0.001,4-6 \mathrm{wk}, p<0.01$ ) (Table 2 ) but did not change between 6 and 8 wk (Table 2). Only $66 \%$ of alveolar duct arteries were muscularized at 8 wk (Fig. $5 A$ ). This was less than in continuously exposed rats (Table $3, p<0.05$ ).

Control rats maintained in RA had the same medial wall thickness (Fig. $5 B$ ) of normally muscular arteries over the duration of the experiment: \% medial wall thickness $=5-7 \%$. Hyperoxia induced significant medial hypertrophy by 4 wk of exposure $(p<0.001$, Fig. $5 B)$ which then became progressively severe between 6 and 8 wk $(p<0.05$, Table 2$)$. Three times normal medial wall thickness was apparent $(p<0.001$, Fig. $5 B)$. This is shown in photomicrographs (Fig. $6 A-C$ ). In rats returned to RA after hyperoxia, three times normal medial wall thickness was observed in the first 2 wk $(p<0.001$, Fig. $5 B)$ but did not progress and at the end of the experiment was only twice normal medial wall thickness $(p<0.01$, Fig. $5 B)$.

In control rats maintained in RA, the axial artery grew in diameter over the first $6 \mathrm{wk}$ of the experiment $(p<0.05-0.001$, Table 2). Hyperoxia caused a decrease in growth of the axial artery by $26 \%$ apparent only by 8 wk of exposure $(p<0.05$, Fig. $5 C$ ). Return to RA after 2 wk of hyperoxia was associated with normal axial artery growth.

\section{DISCUSSION}

Summary of results. Only rats continuously exposed to hyperoxia for $8 \mathrm{wk}$ exhibited failure to thrive and right ventricular hypertrophy. This was associated with the same degree of decreased parenchymal (alveolar) lung growth as rats returned to RA after 2 wk of hyperoxic exposure, but with more severe pulmonary vascular abnormalities. There was further reduction in arterial concentration, more severe muscularization of arteries, and impaired arterial growth occurred.

Lung growth in young rats. That alveoli and arteries grow in bursts during the first month of life in the rat has been previously shown by Meyrick and Reid (16). An additional increase in lung volume and in alveolar number was seen between 4-6 wk. This was not documented in previous studies since the rats were not followed over as long an interval. Meyrick and Reid (17) also showed that hypoxia interferes with the bursts of arterial proliferation. We documented a similar effect of hyperoxia. We observed, as did Roberts et al. (8), that there is incomplete recovery of hyperoxia-induced arterial loss with return to RA; this was apparent even when we followed the rats through their entire period of lung development.

Mechanism of hyperoxic damage to lung parenchyma and pulmonary vasculature. Hyperoxia is thought to cause pathologic changes in the lung since the capacity of the enzymes (e.g. 

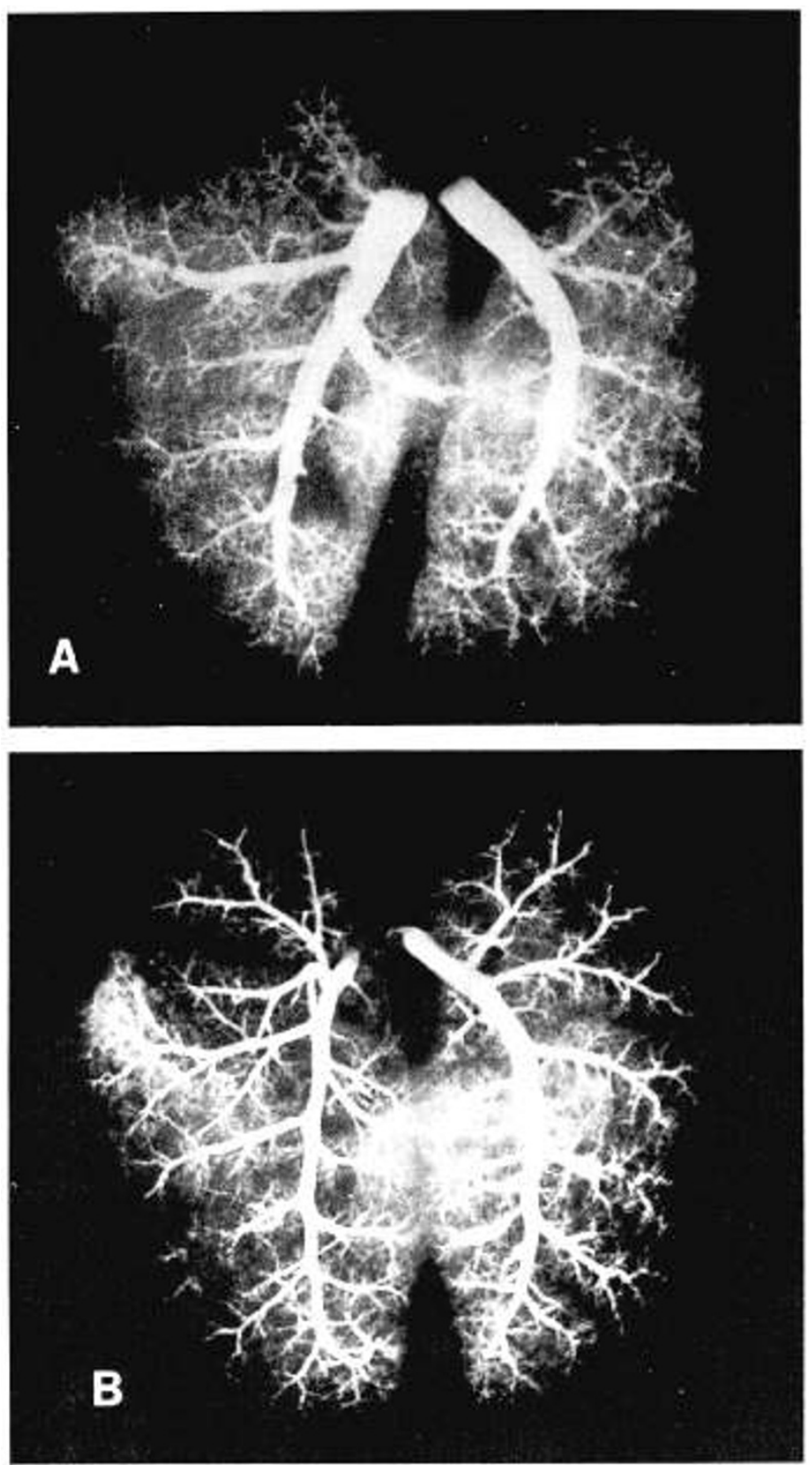

Fig. 4. Arteriograms at $4 \mathrm{wk}$. In $A$ the arteriogram of a 4 -wk RA rat shows the dense background haze of peripheral vessels filled with barium. In $B$ there is a paucity of background haze in the arteriogram of a 4-wk $0.8 \mathrm{FiO}_{2}$ rat.

superoxide dismutase) to reduce cytotoxic superoxide anions is exceeded. Interaction of the free radicals with the protein and lipid components of the endothelial cells is believed to participate in ultrastructural damage to cytoplasmic and organelle membranes manifest by vacuolization and increased lysosomal activity $(18-21)$.

In the mature lung the toxic effects of hyperoxia on pulmonary vascular endothelium decrease the number and size of capillaries and small precapillary arteries. Perhaps this also affects muscularization of normally nonmuscular peripheral arteries and medial hypertrophy of muscular arteries but this is yet to be shown. In the developing lung, the toxic effects of hyperoxia on endothelium may also be expected to lead to impaired arterial growth.

High oxygen is also cytotoxic to epithelial cells causing an increase in free ribosomes, dilatation of the endoplasmic reticu-
Table 3. Morphologic differences between $0.8 \mathrm{FIO}_{2}$ and $0.8 \mathrm{FIO}_{2}+$ $R A$ at $8 w k, p$ values given
A. Growth
$<0.001$
B. $\mathrm{RV} / \mathrm{LV}+\mathrm{S}$
$<0.01$
C. Lung volume
$<0.05$
D. Alveoli $/ \mathrm{mm}^{2}$
-*
E. Total alveolar no.
F. Arteries $/ \mathrm{mm}^{2}$
$<0.001$
G. Arteries/100 alveoli
$<0.001$
$\mathrm{H}$. Extension of muscle
$<0.05$
I. Medial hypertrophy
J. Lumen diameter
$<0.05$

$* p \geq 0.05$.

lum, and mitochondrial changes in type II epithelial cells in neonates (21) and in mature animals $(22,23)$. In the mature lung, these features, associated with initial hypertrophy and hyperplasia of the type II cells, and with later degeneration, desquamation, and fibrosis, result in a decrease in alveolar surface area. In the developing lung the toxic effects on epithelium may also inhibit alveolar growth (7).

It is tempting to speculate that in addition to the purely toxic effects of hyperoxia, some of the abnormalities observed in the developing lung may be the result of initial physiologic adaptations. Enhanced availability of $\mathrm{O}_{2}$ may inhibit alveolar and arterial proliferation. Animals returned to RA have impaired alveolar development presumably because the stimulus for their proliferation has been lost during the initial hyperoxic exposure. We speculate that continued muscularization of arteries occurs, conceivably, because now the room air environment is sensed as "relatively hypoxic," as implied by Roberts et al. (8) in their study. We also speculate that because the toxic effect of high oxygen on vascular endothelium is removed, the degree of abnormal extension of muscle and of medial hypertrophy is less than in continuously exposed animals.

Effect of increasing duration of hyperoxia on lung and vascular growth. In our study failure to thrive only occurred with increasing duration of hyperoxia. While it may have reflected a generalized organ response, it was indeed associated with the development of right ventricular hypertrophy and progressively severe vascular changes, e.g. "extension" of muscle into peripheral arteries, medial hypertrophy of muscular arteries, and reduced arterial concentration and size. There was no accompanying evidence of right heart failure, i.e. ascites or edema.

The fact that the extension of muscle and medial hypertrophy was severe at $4 \mathrm{wk}$, reduced at $6 \mathrm{wk}$, and then became severe again at $8 \mathrm{wk}$ suggests that the developing lung exposed to hyperoxia may show some initial adaptation. However, further endothelial injury may lead to progressive vascular changes. The decreased lumen diameter of the axial artery by $8 \mathrm{wk}$ suggests that with prolonged exposure the macrocirculation will also be affected.

Effect of return to normoxia. Although the hyperoxic insult is removed after $2 \mathrm{wk}$, further adverse effects become apparent on return to room air, i.e. inhibition of lung growth and increased muscularization of arteries. These changes were, however, not of a severity to be manifest as failure to thrive or RV hypertrophy. When lung volumes were analyzed along with alveolar concentration, there is evidence of a smaller lung with fewer alveoli, suggesting a different adaptive response than in the continuously hyperoxia exposed rats. We cannot explain why rats returned to RA did not have a less severe decrease in alveolar number than rats continuously exposed to hyperoxia, since the latter animals would be expected to show further evidence of toxic damage to alveoli. We can only speculate that in the developing lung there is adaptation to or inhibition of alveolar damage resulting from continued exposure to hyperoxia. This is supported by findings 

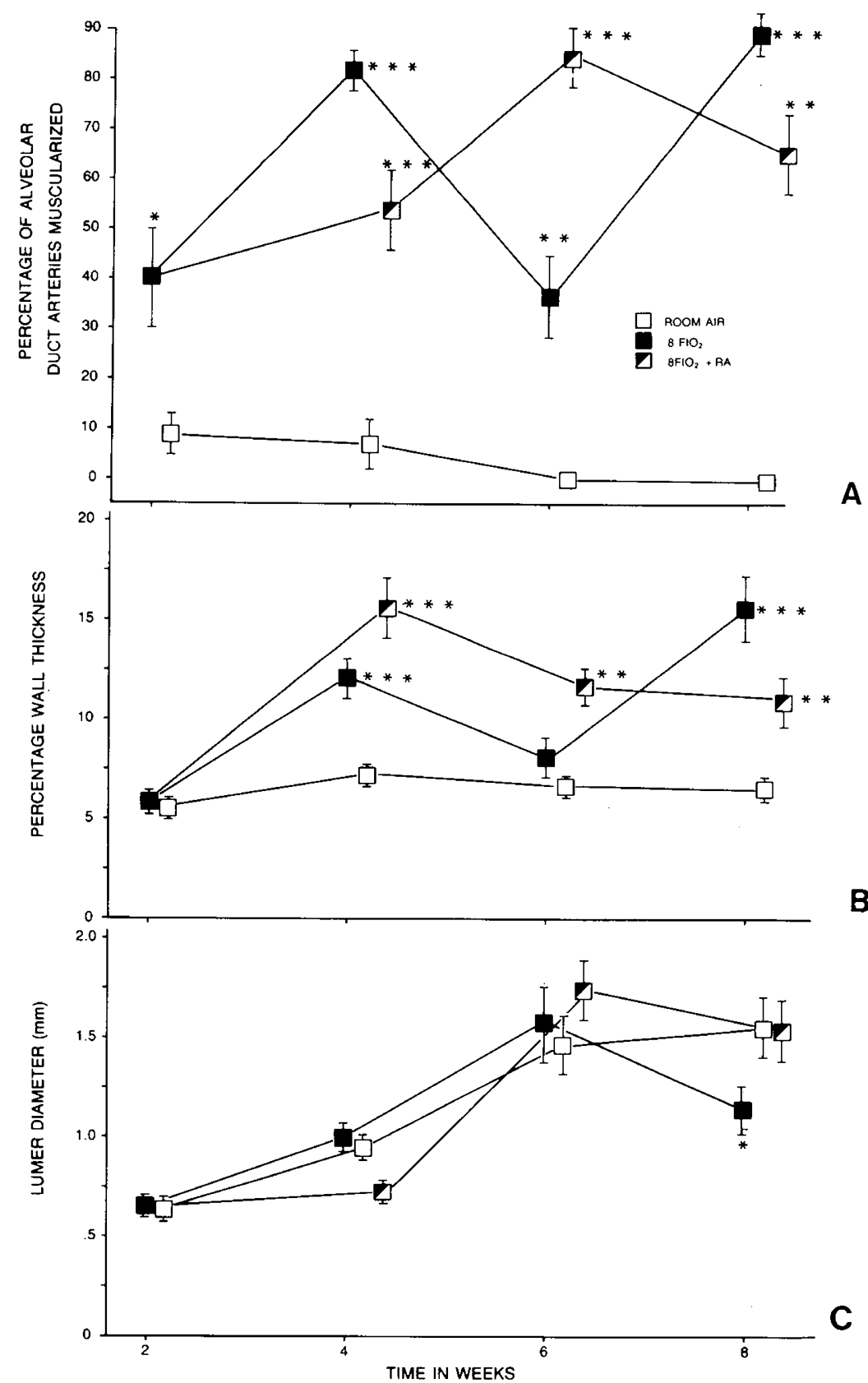

Fig. 5. $A$, extension of muscle. In RA rats, a small percentage of alveolar duct arteries were muscularized: $0.8 \mathrm{FiO}_{2}$ rats had abnormal extension of muscle into peripheral vessels by 2 wk exposure $\left({ }^{*} p<0.05\right)$, which increased further at 4 wk $(p<0.001$, Table 2$)$ and showed only transient decrease at $6 \mathrm{wk}\left(p<0.01\right.$, Table 2). In $0.8 \mathrm{FiO}_{2}+\mathrm{RA}$ rats, extension of muscle was progressively severe for the first 4 wk in RA following exposure $(p<0.001$, Table 2), then showed a trend toward a decrease. $B$, medial hypertrophy. RA control rats maintained the same medial wall thickness (percentage wall thickness) of normally muscular arteries $\left(100-200 \mu \mathrm{m}\right.$ range) over the duration of the experiment: $0.8 \mathrm{FIO}_{2}$ rats had significant medial hypertrophy by $4 \mathrm{wk}$ of exposure relative to controls $(p<0.001)$, which regressed minimally at 6 wk and then became more severe ( $p<$ 0.05 , Table 2). In $0.8 \mathrm{FrO}_{2}+\mathrm{RA}$ rats, severe medial hypertrophy occurred after 2 wk return to RA which showed evidence of regression over the next 2 wk $(p<0.05$, Table 2$)$ but did not change thereafter. $C$, axial artery lumen diameter $50 \%$ from hilum. In $\mathrm{RA}_{\text {control and } 0.8 \mathrm{FiO}}+\mathrm{RA}$ rats, the axial artery grew in diameter during the first $6 \mathrm{wk}$ of the experiment. In $0.8 \mathrm{FiO}_{2}$ rats, there was a decrease in the lumen diameter of the axial artery apparent after $8 \mathrm{wk}$ of exposure $(p<0.05)$.

of Frank (2) in young rats which show induction of antioxidant enzymes with increasing duration of hyperoxic exposure.

Unlike the alveoli which remain compromised in their ability to proliferate normally, pulmonary arteries return to normal concentration in young rats returned to RA. This may reflect the ability of the developing lung to adapt to impaired ventilation by establishing more favorable perfusion. While posthyperoxic angiogenesis has been documented by Roberts et al. (8) in neonatally exposed rats, catch-up arterial growth has also been described following takedown of a surgically created systemic to pulmonary artery shunt in a young animal $(24,25)$.

While the arteries "recovered" in number during return to RA, medial hypertrophy and extension of muscle into peripheral arteries showed an initial tendency to be more severe than in rats continuously exposed to hyperoxia. Later, these features regressed but did not return to normal. The increased muscularity 


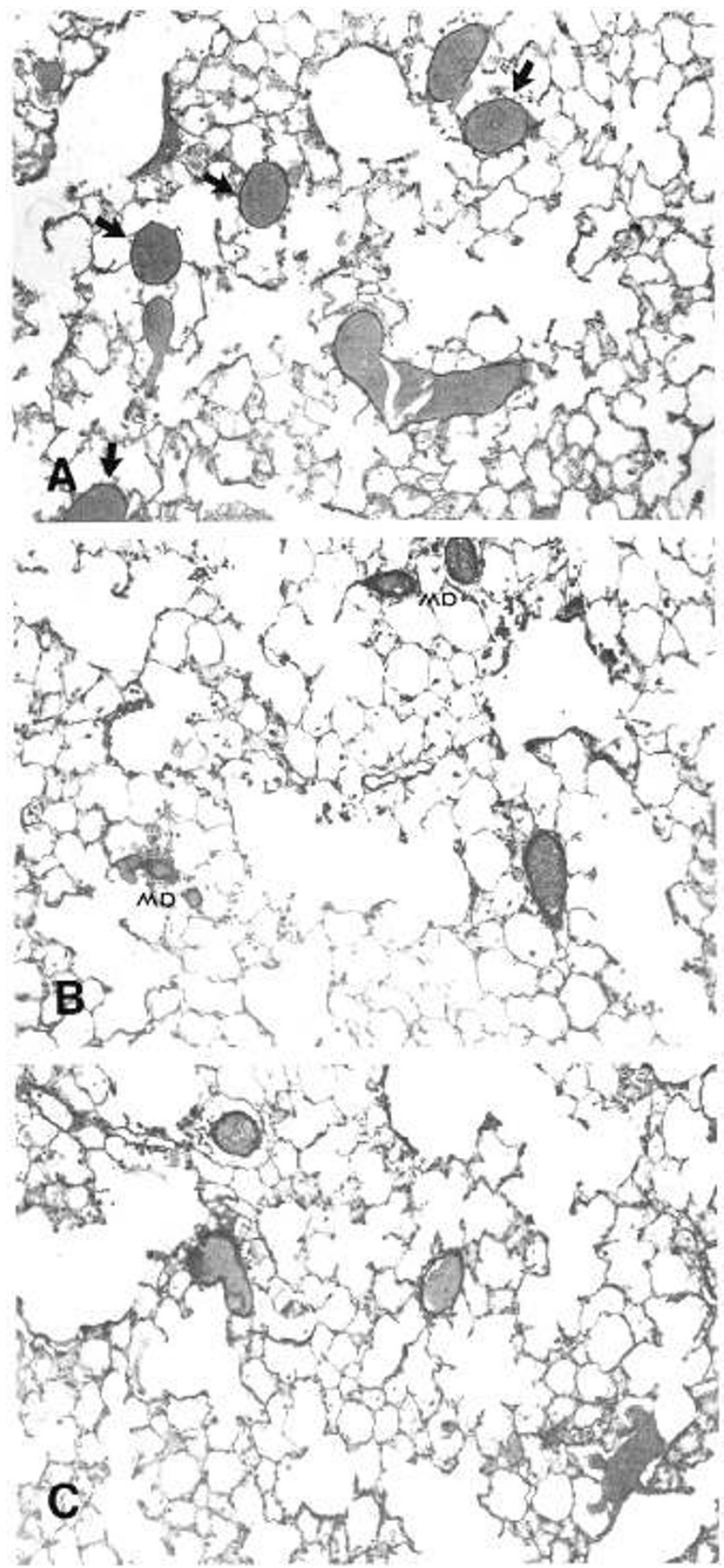

Fig. 6. $A$, photomicrographs of barium injected lung tissue showing numerous nonmuscular alveolar duct arteries (arrow) and numerous alveoli from control room air rat at the end of the experimental period ( $8 \mathrm{wk}) . B, 0.8 \mathrm{FIO}_{2}$ rat after $8 \mathrm{wk}$; there are few alveolar duct and wall $(A W)$ arteries that are abnormally muscularized and fewer alveoli then in control. $C, 0.8 \mathrm{FiO}_{2}+\mathrm{RA}$ rat after 8 wk. Arteries are more numerous than in $0.8 \mathrm{FIO}_{2}$ rat but still show abnormal muscularity. There are fewer alveoli compared with the control lung. Magnification $\times 640$; elastic Van Gieson stain for each.

may therefore be the result of the animals reacting to $\mathrm{RA}$ as relative hypoxia by pulmonary vasoconstriction. Our previous studies of rats exposed to hypobaric hypoxia suggest that abnormal muscularization of pulmonary arteries is associated with a change in hemodynamics (26-28).
In rats returned to RA, it seems that neither the vascular changes nor the impaired lung growth were of sufficient severity to be manifest overtly in failure to thrive or right ventricular hypertrophy. These rats had "hidden" lung damage which may have been associated with a decreased compliance (7) and may have become apparent with stress or further compromise, e.g. infection.

Clinical implications. On the basis of these studies, we suggest that perhaps in infants with bronchopulmonary dysplasia, the pulmonary vascular changes resulting in cor pulmonale, may in part be due to exposure to high oxygen. Perhaps, relatively short hyperoxic exposures can result in permanent alveolar damage and vascular changes which may not be manifest in overt symptomatology such as failure to thrive or RV hypertrophy but which may be associated with abnormal lung compliance as shown by Bryan et al. (29) or with heightened pulmonary vascular reactivity. Perhaps infants treated with oxygen therapy may be at greater risk if they develop infection, have a congenital heart defect associated with a left to right shunt, or live at high altitude. Perhaps later they will have limitations with exercise.

As a first step, it will be important in future experimental studies to determine whether rats returned to RA have abnormal pulmonary function at rest or with exercise or have heightened pulmonary vascular reactivity. On the basis of results of these studies, we may have more cause to pursue assessment of these parameters in patients who have been exposed to high oxygen during the period of lung development.

Acknowledgments. The authors gratefully acknowledge the help and advice of Dr. Margaret M. Wood, biostatistician, The Hospital for Sick Children and Professor William Friend, Department of Zoology, University of Toronto. We also thank Ms. Pamela Longley for her secretarial assistance as well as Ms. Eva Struthers and Mr. Ray Caesar for the illustrations.

\section{REFERENCES}

1. Fisher AB 1982 Molecular mechanism of pulmonary oxygen toxicity. In Prakash O (ed) Applied Physiology in Clinical Respiratory Care. Martinus Nijhoff, The Hague, Netherlands, pp 17-26

2. Frank $\mathrm{L} 1982$ Protection from $\mathrm{O}_{2}$ toxicity by pre-exposure to hypoxia: lung antioxidant enzyme role. J Appl Physiol 53: 475-482

3. Rosenfeld W, Evans M, Concepcion L, Jhaveri R, Schaeffer H, Friedman A 1984 Prevention of bronchopulmonary dysplasia by administration of bovine superoxide dismutase (SOD). Pediatr Res 18:160A(abstr)

4. Stevens JB, Autor AP 1980 Proposed mechanism for neonatal rat tolerance to normobaric hyperoxia. Fed Proc 39:3138-3143

5. Davis BW, Rennard SI, Bitterman PB, Crystal RG 1983 Pulmonary oxygen toxicity, early reversible changes in human alveolar structures induced by hyperoxia. N Engl J Med 309:878-883

6. Reid L 1979 Bronchopulmonary dysplasia-pathology. J Pediatr 95:836-841

7. Bucher JR, Roberts RJ. 1981 The development of the newborn rat lung in hyperoxia. A dose response study of lung growth, maturation and changes in antioxidant enzyme activities. Pediatr Res 15:999-1008

8. Roberts RJ, Weesner KM, Bucher JR 1983 Oxygen-induced alterations in lung vascular development in the newborn rat. Pediatr Res 17:368-375

9. Jones R, Zapol WM, Reid L 1984 Pulmonary artery remodelling and pulmonary hypertension after exposure to hyperoxia for seven days. Am J Pathol $117: 273-285$

10. Frank L, Bucher JR, Roberts RJ 1978 Oxygen toxicity in neonatal and adult animals of various species. J Appl Physiol 45:699-704

11. Hislop A, Reid L 1976 New findings in pulmonary arteries of rats with hypoxia induced pulmonary hypertension. Br J Exp Pathol 57:542-554

12. Fulton RM, Hutchinson EC, Jones AM 1952 Ventricular weight in cardiac hypertrophy. Br Heart J 14:413-420

13. Dunnill MS 1962 Quantitative methods in the study of pulmonary pathology. Thorax 17:320-328

4. Weibel ER, Gomez DM 1962 A principle for counting tissue structures on random sections. J Appl Physiol 17:343-348

15. Kramer CY 1956 Extension of multiple range tests to group means with unequal numbers of replication. Biometrics 12:307-310

16. Meyrick B, Reid L 1982 Pulmonary arterial and alveolar development in normal postnatal rat lung. Am Rev Respir Dis 125:468-473

17. Meyrick B, Reid L 1981 The effect of chronic hypoxia on pulmonary arteries in young rats. Exp Lung Res 2:257-271

18. Clark JM, Lambertson CJ 1971 Pulmonary $\mathrm{O}_{2}$ toxicity: a review. Pharmacol Rev 23:37-121

19. Crapo JD, Barry BE, Foscue HA, Shelburne J 1980 Structural and biochemica 
changes in rat lungs occuring during exposures to lethal and adaptive dosages of oxygen. Am Rev Respir Dis 122:123-143

20. Lee SL, Douglas WHJ, Keneke SM, Fanburg BL 1983 Uitrastructural changes in bovine pulmonary artery endothelial cells exposed to $80 \% \mathrm{O}_{2}$ in vitro. In Vitro 19:714-722

21. Pappas CTE, Obara H, Bensch KG, Northway WH 1983 Effect of prolonged exposure to $80 \%$ oxygen on the lung of the newborn mouse. Lab Invest 48:735-748

22. Kistler GS, Caldwell PRB, Weibel WR 1967 Development of fine structural damage to alveolar and capillary lining cells in oxygen poisoned rat lungs. $\mathrm{J}$ Cell Biol 32:605-628

23. Rosenbaum RM, Wittner M, Lenger M 1969 Mitochondrial and other ultrastructural changes in great alveolar cells of oxygened adapted and poisoned rats. Lab Invest 20:516-28

24. Rabinovitch M, Keane JF, Norwood WI, Castaneda AR, Reid L 1984 Vascular structure in lung tissue obtained at biopsy correlated with pulmonary hemo- dynamic findings after repair of congenital heart defects. Circulation 69:655667

25. Rendas A, Reid L 1983 Pulmonary vasculature of piglets after correction of aorta-pulmonary shunts. J Thorac Cardiovasc Surg 85:911-916

26. Rabinovitch, M, Gamble W, Nadas A, Miettinen OS, Reid L 1979 Rat pulmonary circulation after chronic hypoxia: hemodynamic and structural features. Am J Physiol 236:818-827

27. Rabinovitch M, Gamble W, Miettinen OS, Reid L 1981 Age and sex influence on pulmonary hypertension of chronic hypoxia and on recovery. Am J Physiol 240:H62-H72

28. Rabinovitch M, Konstam MA, Gamble WJ, Papanicolaou N, Aronovitz MJ, Treves S, Reid L 1983 Changes in pulmonary blood flow affect vascular response to chronic hypoxia in rats. Circ Res 52:432-441

29. Bryan MH, Hardie MJ, Reilly BJ, Swyer PR 1973 Pulmonary function studies during the first year of life in infants recovering from the respiratory distress syndrome. Pediatrics 52:169-178 